\title{
A obra literária na era da explosão de signos: uma proposta semiótica de análise do romance
}

Sergio Ricardo Lima de Santana

\section{Resumo}

Este artigo propõe uma abordagem metodológica do romance sob o ponto de vista da semiótica de Charles Sanders Peirce, utilizando como parâmetros as categorias universais da primeiridade, secundidade e terceiridade para análise do texto literário. É realizada uma breve análise do romance $\mathrm{O}$ talentoso Ripley, de Patricia Highsmith, com o intuito de demonstrar a aplicabilidade e pertinência da metodologia proposta. Pôde-se concluir que, diante da complexidade contemporânea no que se refere à multiplicação de signos, a abordagem pode trazer vantagens, ao tornar necessária a análise dos aspectos do romance, sem desprezar a participação da própria subjetividade do analista.

Palavras-chave: Romance; semiótica; metodologia 


\section{Introdução}

A ideia da qual partimos aqui é que, dentro de um contexto de explosão semiótica, no qual os signos multiplicam-se continuamente e desafiam nossa capacidade de compreensão, qualquer arte ou linguagem, assim como qualquer obra em particular, é uma tradução de outros signos, por meio de um código relativamente específico. Esta ideia tem implicações: primeiramente, torna necessário que consideremos a literatura dentro de uma rede semiótica, indissociável dos outros saberes, artes e ciências, com os quais necessariamente ela interage. Em segundo lugar, lembranos de que, ainda que assim o seja, a literatura e sua teoria têm suas próprias convenções, tradições e vocabulário, com os quais precisamos lidar para tornar possível algum entendimento e uma comunicação sobre o assunto. Além disso, chama atenção para o fato de que uma realização particular - como um romance, ou uma crítica, ou uma adaptação cinematográfica de um romance, entre outras - pode ser considerada uma atualização da literatura, ao desvendar e produzir novos signos, dentro da grande rede semiótica e diante de todos os outros textos existentes.

Já se constitui um lugar-comum afirmar que, no mundo atual, os sistemas de signos se multiplicam, e é necessário criar ferramentas para compreender e lidar com os signos em constante produção. Podemos perceber que, tanto os romances produzidos contemporaneamente, como as leituras e releituras atuais de romances atuais ou antigos, estão impregnados dessa qualidade, ou seja, tanto na sua forma, quanto no seu conteúdo, é provável que reproduzam a característica atual de produção constante, em ritmo exponencial, de novos signos. Diante disso, algumas perguntas podem ser colocadas: Primeiramente, de quais ferramentas, por exemplo (uma vez que não há limites para as possibilidades), podemos nos munir, a fim de adquirirmos a competência para lidarmos com tal criação frenética de signos? Em segundo lugar, até que ponto é possível ou necessário nos dedicarmos à rede semiótica como um todo, ou nos atermos a determinados limites que denominamos estudos de literatura? Parece ser necessário que encontremos uma abordagem que esteja na interseção entre o reconhecimento do todo - a rede semiótica - e a concentração em uma subrede mais específica - a literatura e os estudos literários. Tendo isto em vista, nosso objetivo neste artigo é delinear uma possível metodologia para a análise do texto literário, mais particularmente o romance.

Para isso, nossa proposta é a aplicação de conceitos da semiótica peirciana, com o intuito de forjar um método de análise do texto literário envolvendo três níveis de significação, correspondentes às categorias peircianas da primeiridade, secundidade e terceiridade. O filósofo norte-americano Charles Sanders Peirce desenvolveu uma teoria semiótica com um caráter bastante geral 
e abstrato (SANTAELLA, 1992, p. 43). Dessa forma, sua teoria não visa a uma aplicação prática (SANTAELLA, 2005, p. XI; XII); antes, Peirce buscou desenvolver uma semiótica, que ele mesmo chamava de lógica, a qual procurava, entre outras coisas, investigar o modo como apreendemos algo com que nos deparamos. Isso significa que a sua proposta se voltava à compreensão do processo de pensamento mais que à investigação sobre um sistema de signos em particular. Ainda assim, podemos utilizar a lógica estabelecida por Peirce para abordarmos o texto literário de acordo com a sua suposta especificidade e, ao mesmo tempo, dentro de um contexto semiótico complexo e em constante mutação.

As categorias peircianas mencionadas acima configuram uma lógica que procura dar conta de como se dá o fenômeno da significação; de certa forma, constituem a base da fenomenologia peirciana. Para Peirce, um Terceiro é algo que traz um Primeiro para uma relação com um Segundo. Podemos considerar o Terceiro como sendo um resultado (parcial) do processo de significação. O Primeiro, relacionado à categoria da primeiridade, é algo apresentado de forma imediata, aquilo que está presente como uma impressão ou sentimento; o Segundo (secundidade) é a relação ou embate que se estabelece, por exemplo, na tentativa de compreensão do Primeiro; o Terceiro (terceiridade) relacionase à camada da inteligibilidade, do conhecimento racional, da interpretação.

À qualidade do signo corresponde a categoria universal da primeiridade, a qual se relaciona à percepção ou sensação, à possibilidade de significação. A existência singular remete à secundidade, categoria associada ao campo da experiência e da ação, ou seja, à realidade. Por fim, ao caráter de lei corresponde a terceiridade, categoria que está ligada ao pensamento, à convenção, à apreensão racional e à necessidade (WALTHER-BENSE, 2000, p. 3; LIMA DE SANTANA, 2009, p. 29).

De acordo com a mesma lógica, Peirce define o signo como uma tríade formada pelo representamen - que é o signo propriamente dito -, o objeto que ele representa e o interpretante, que é forma como o signo se configura na mente de alguém (PEIRCE apud SANTAELLA, 2004, p. 12). O objeto só existe enquanto tal quando veiculado por um representamen e gerar uma imagem mental. Do mesmo modo, um signo só pode ser considerado signo se houver um objeto que seja por ele manifestado segundo alguma concepção. Assim como só existe um interpretante se for veiculado por um signo, ao denotar um objeto. Deve-se esclarecer que um interpretante não deve ser confundido com uma interpretação, sendo antes uma relação lógica necessária para que o signo possa ser definido como tal. A semiose não está confinada à necessidade de um interpretante mental, o que não quer dizer que o intérprete seja desprezível ou inexistente (SANTAELLA, 1992, p. 189). 
Em relação ao objeto representado, o signo pode ser um ícone, quando imita a aparência do objeto, estabelecendo com ele uma relação de semelhança e despertando sensações análogas; um índice, quando apresenta uma conexão ou uma relação de causa e efeito com o objeto, estando organicamente ligado a ele; ou um símbolo, quando representa o objeto por uma convenção ou lei, que deve ser aprendida para que o signo funcione, de fato, como símbolo (PEIRCE, 1999, p. 73).

Partindo dessa lógica, podemos propor a análise do romance da seguinte maneira: o conjunto de elementos próprios do romance ligados à construção de uma atmosfera, às sensações e sentimentos (primeiridade), formariam uma base da qual partiríamos para observar a relação entre o romance e os existentes, sejam estes referências à chamada realidade ou simplesmente inventados pelo autor, bem como a outros textos os mais variados (secundidade); finalmente, tal observação nos daria subsídios para traçarmos conjecturas sobre os conceitos trazidos pelo romance, sobre possíveis significados (terceiridade).

E possível notar que tanto os elementos imediatos e formais, os quais se relacionam à primeiridade; quanto os dêiticos, narrativos, factuais ou intertextuais, ligados à secundidade; assim como os conceituais e convencionais, os quais correspondem à terceiridade, apontam para uma comunicação ou interação com os processos de construção sígnica em funcionamento no mundo. Isto significa que a análise de obras artísticas atuais potencialmente revela os signos contemporâneos ligados ao sentimento e à impressão, ao embate e à luta pela compreensão e desenvolvimento de uma ideia, bem como à convenção e à inteligibilidade.

Entretanto, exatamente por estarmos impregnados dos signos de nossa própria época, o contrário também acontece: tendemos a identificar elementos icônicos, indexicais e simbólicos mais significativos do ponto de vista da época da leitura. Daí porque podemos sugerir que uma crítica diz mais sobre a época em que ela (a crítica) surge do que sobre a obra criticada. Consequentemente, a análise de obras artísticas, sejam elas contemporâneas ou não, potencialmente revela, em grande parte, signos próprias da contemporaneidade.

As próximas seções apresentam uma proposta metodológica para abordagem do texto literário, mais especificamente o romance, e a aplicação da referida proposta na análise do romance O talentoso Ripley, da escritora norte-americana Patricia Highsmith (1921-1995). Finalmente, alguns comentários adicionais concluem este trabalho.

\section{Proposta metodológica de análise do romance}

Um romance pode ser visto como uma tradução de uma história ou de uma ideia para a linguagem literária. Ao mesmo 
tempo, podemos considerar que uma tradução é uma crítica, a qual faz o texto-fonte necessariamente passar por uma série de operações (seleção, recorte, transformação, recriação, conformação etc), para gerar o texto-alvo. Portanto, um romance é uma crítica, seja da estética, dos conceitos ou da moral relacionados à história contada. Sendo uma crítica, fala principalmente de sua própria época e contexto. Utiliza-se de signos icônicos, indexicais e simbólicos próprios de seu tempo e espaço.

Também, uma leitura (ou interpretação) de um romance é uma tradução para a complexidade do pensamento, uma atualização, uma crítica, que fala mais sobre o(a) próprio(a) leitor(a), sua época e referências, do que sobre o romance em si. Assim como, por exemplo, uma adaptação cinematográfica é também uma tradução, uma crítica, que revela principalmente a maneira de ver o mundo, as aspirações e interesses dos realizadores (diretor, roteirista, produtores etc) do filme (LIMA DE SANTANA, 2009, p. 116).

É interessante notar que a fortuna crítica de um romance, por meio da crítica propriamente dita, da leitura, da adaptação cinematográfica e tradução para outros sistemas de signos - ou seja, da sua constante atualização - é em grande parte responsável pela sua importância no conjunto da cultura e pelas significações que lhe são atribuídas. Por extensão, concorre também para a afirmação do gênero romance e do próprio sistema de signos literário. Assim, há uma conexão indissociável entre o romance e os demais sistemas de signos que participam do contexto no qual ele surge. Do mesmo modo, há uma ligação necessária entre a leitura, a crítica ou a análise do romance e os sistemas de signos que formam o contexto no qual tais atividades se realizam. Isto posto, podemos enumerar, em correlação com as categorias peircianas e levando em conta a capacidade que elas apresentam de, simultaneamente, considerarem o todo e o específico, três momentos de uma análise literária, os quais poderiam constituir um método de análise possível:

1) A percepção da forma como o romance veicula sentimentos, sensações, especialmente a uma primeira vista e com respeito àquilo que é imediatamente apresentado, provocando impressões que escapam à racionalidade. Em outras palavras, quais são os atributos ou signos icônicos do romance, aqueles que tendem a colaborar na formação de uma atmosfera, na veiculação ou produção de sentimentos?

2) A identificação do processo de atualização provocado pelo romance na sua construção, isto é, dos elementos que se conjugam para construir uma narrativa, das referências textuais e intertextuais particulares da obra em questão. Trata-se aqui dos elementos indexicais, dos 
índices que conectam o romance com o mundo, veiculam ou criam um embate na direção do significado e possibilitam a compreensão por parte do(a) leitor(a).

3) A interpretação gerada a partir das análises anteriores ou, colocando-se de outro modo, a sugestão de um significado, ainda que transitório e relativo, por ser particular e pontual e por estar sujeito à cadeia de significados próprios do contexto onde a interpretação é feita. Quais são as ideias que o romance defende ou que lhe são subjacentes?

É necessário ressaltar que nem o romance, conforme salientamos, nem a sua análise, estão isentos da infindável rede sígnica estabelecida. Assim como o romance traduz determinados sentimentos, narrativas e ideias sob a influência de um contexto maior, também sua análise sofre ação de um contexto semiótico próprio do período, lugar e situação em que é feita. Uma vez que nossa época procura abrir espaço para diferentes discursos, ao invés de aceitar ou assumir um discurso hegemônico e central, uma análise contemporânea tende a buscar no romance diversos discursos explícitos ou implícitos. Similarmente, é plausível que as análises literárias tornem-se cada vez menos profundas e abrangentes e se voltem mais a aspectos específicos, assumindo um formato de comentários hipertextuais, à medida que nosso aparelho sensorial vai se acostumando cada vez mais com as mídias digitais, sua alta capacidade de armazenamento e recuperação de informações, com a aceleração do tempo e as mudanças constantes, as interfaces gráficas e hipertextos.

Na próxima seção, aplicamos os procedimentos acima especificados em uma breve análise do romance $O$ talentoso Ripley, da escritora norte-americana Patricia Highsmith.

\section{Três vezes Ripley}

Apesar da aversão que Hollywood lhe inspirava na época, Patricia Highsmith considerava-se afortunada por Alfred Hitchcock ter se interessado em adaptar o romance Pacto sinistro, escrito em 1951. Embora ela não tenha recebido royalties, uma vez que o cineasta adquiriu direitos perpétuos sobre o romance, essa adaptação foi um marco fundamental para que a escritora passasse a ser reconhecida e cultuada (CINÉMA, 1988).

Nas narrativas policiais de Highsmith, a maior parte das ações se dá na mente dos seus principais personagens. São os sentimentos, os reflexos, a intuição, os pensamentos mais secretos dos personagens centrais que conferem às suas narrativas a atmosfera de suspense e tensão. Em virtude disso, o(a) leitor(a) é incitado(a) a se identificar com as suas razões e ações, mesmo que não necessariamente as aprove do ponto de vista ético.

Um exemplo disso é a potencial cumplicidade que se pode estabelecer com o personagem principal da série Ripley, composta 
por cinco romances. Em Nova York, o jovem Ripley do primeiro romance (O talentoso Ripley [The talented Mr. Ripley], publicado em 1955) recebe uma proposta do empresário Herbert Greenleaf: Ele deve ir à Europa para tentar convencer o filho de Herbert, Dickie Greenleaf, que vive na pequena cidade de Mongibello com sua namorada Marge, a voltar para os Estados Unidos e reassumir suas obrigações, dando continuidade aos negócios do pai. A oferta é vista por Ripley como uma possível saída para sua difícil situação financeira, uma vez que já pensava em deixar Nova York, onde vive em um apartamento sujo e decadente. Nesta cidade, Ripley leva uma vida difícil e sem perspectivas; não tem emprego fixo, faz pequenos bicos e aplica alguns golpes para tentar sobreviver.

Na Europa, Ripley conquista a confiança e a amizade de Dickie, contando-lhe os planos de Herbert Greenleaf. Ripley se fascina por Dickie e sua forma de viver. Faz planos para continuar desfrutando dos prazeres da vida na Europa. Porém, após algum tempo de convívio, em um momento de rejeição, no qual Dickie deixa claro que a brincadeira terminou, a reação de Ripley é matar o rapaz e assumir a sua identidade. Posteriormente, assassina também Freddie Miles, o desconfiado amigo de Dickie que lhe aparece como um obstáculo. Com seu talento para imitar assinaturas, bem como sua inteligência para se esquivar das desconfianças, Ripley não somente sai impune dos homicídios, como ainda forja uma carta, supostamente escrita por Dickie, deixando-lhe uma significativa herança, em agradecimento pela sua fiel amizade.

Em O talentoso Ripley, podemos encontrar signos que potencialmente conectam-se à ordem do sentimento, da sensação e da incerteza. Além disso, há signos que apontam para outros objetos, como índices do mundo do qual o romance emerge. A partir desses signos, é possível realizar uma análise que nos permita estabelecer algum nível de generalização ou interpretação, a qual pode funcionar como um novo signo que, por definição, não se esgota, mas que gera novas significações ad infinitum.

\subsection{Análise de signos icônicos}

No primeiro caso, é possível sugerir que, na linguagem literária, que tem como matriz a linguagem escrita, é com dificuldade que o(a) analista consegue se desprender dos aspectos racionais, lógicos e sintagmáticos, para identificar aquilo que foge à regra, que não obedece a uma determinada ordem ou convenção e, dessa maneira, assume potencialmente outras possibilidades. Aquilo que não pode ser generalizado, que estabelece uma relação icônica com seu objeto, são especialmente as questões ligadas à forma, ao caráter qualitativo da narrativa e, finalmente, às descrições e metáforas (SANTAELLA, 1980, p. 151; LIMA DE SANTANA, 2009, p. 75-76). 
Uma narrativa que se imiscui e desvia a atenção do que está sendo narrado para qualificar o personagem, por exemplo, estabelece uma relação com o objeto da narração que não se determina de maneira totalmente lógica, predominando nela o nível da sensação, da possibilidade. Por exemplo, quando, no romance, Ripley está no navio a caminho da Europa, ele escreve uma carta para sua Tia Dottie, fato que o faz sentir-se melhor, pois representa para ele uma forma de se separar definitivamente dela. Ao relembrar momentos desagradáveis, nos quais Tia Dottie o humilhava ou diminuía, a narrativa opera, ao mesmo tempo, como um comentário que dá informações a mais sobre o personagem, como um desvio que enseja novas possibilidades e sensações:

Ele não precisava contar para ela onde ele estava. Não haveria mais cartas maliciosamente sarcásticas, comparações dissimuladas entre ele e seu pai, os cheques de somas estranhas como seis dólares e quarenta e oito e doze dólares e noventa e cinco, como se ela tivesse ficado com um restinho da última vez que pagou uma conta ou devolvido algo a uma loja e atirado o dinheiro para ele, como uma migalha [...] Tia Dottie insistia que sua educação tinha custado a ela mais do que o pai dele tinha deixado de seguro, e talvez tenha, mas ela precisava ficar passando na cara dele? (HIGHSMITH, 1999, p. 37). ${ }^{1}$

De repente ele pensou em um dia de verão quando ele tinha doze anos, na ocasião em que ele tinha viajado com Tia Dottie e uma amiga dela e eles ficaram presos em algum lugar, em um lento engarrafamento. Era um dia quente de verão e Tia Dottie o tinha mandado sair com uma garrafa térmica para buscar água gelada em um posto de gasolina, e repentinamente o trânsito começou a andar. Ele se lembra de ter corrido entre carros enormes que se deslocavam aos poucos, sempre perto de tocar na porta do carro de Tia Dottie e nunca conseguindo, porque ela continuava deslocando o carro o mais rapidamente que podia, incapaz de parar por um minuto e gritando, 'Anda, anda, sua lesma!' (p. 37-38)².

Ele lembrava a promessa que fez, mesmo aos oito anos de idade, de fugir de Tia Dottie, as cenas violentas que ele imaginava Tia Dottie tentando segurá-lo na casa e ele batendo nela com os punhos, jogando-a no chão e estrangulando-a, e finalmente arrancando um grande broche do vestido dela e cravando-o um milhão de vezes na garganta dela (p. 39) ${ }^{3}$.

Essas narrativas espaciais (SANTAELLA, 2005, p. 326) atuam na estrutura do romance, na sua materialidade, dando lugar a impressões subjetivas e afastando o romance do domínio da lógica sintagmática da linguagem escrita. O caráter qualitativo é responsável pela quebra da linearidade dos eventos por meio do uso de organizações paralelísticas que provocam uma multiplicidade de visões sobre um mesmo evento.

No romance em questão, diversas narrativas qualitativas, acontecimentos hipotéticos e descrições contribuem para a 
construção sensorial da atmosfera, como, por exemplo, a seguinte passagem, na qual o narrador revela o que se deduz ser o pensamento e o sentimento de Ripley enquanto este cogita e planeja o assassinato de Dickie:

A água. Mas Dickie era tão bom nadador. Os penhascos. Seria fácil empurrar Dickie de algum penhasco enquanto eles caminhassem, mas ele imaginou Dickie se agarrando a ele e puxando-o consigo, e ele enrijeceu na cadeira até que seus músculos doessem e suas unhas formassem conchas vermelhas nos seus polegares. Ele teria que tirar o outro anel também. Mas ele não viveria em um lugar claro, onde morasse alguém que conhecesse Dickie. Ele só tinha que parecer com Dickie o suficiente para usar o seu passaporte (HIGHSMITH, 1999, p. 100-101). ${ }^{4}$

A ação não se converte em fato na narrativa, mas no pensamento do personagem, revelado pelo narrador. A narrativa assume um caráter qualitativo, aproximando o(a) leitor(a) do personagem. Assim, o(a) leitor(a) se torna o único a saber o que se passa na mente de Ripley e, portanto, estabelece com ele uma relação de cumplicidade. Não pode denunciar - e talvez nem

4 The water. But Dickie was such a good swimmer. The cliffs. It would be easy to push Dickie off some cliff when they took a walk, but he imagined Dickie grabbing at him and pulling him off with him, and he tensed in his seat until his thighs ached and his nails cut red scallops in his thumbs. He would have to get the other ring off, too. But he wouldn't live in a place, of course, where anybody who knew Dickie lived. He has only to look enough like Dickie to be able to use his passport. Well, he did. If he - (HIGHSMITH, 1999, p. 100-101).

5 San Remo. Flowers. A main drag along the beach again, shops and stores and French and English and Italian tourists. Another hotel, with flowers in the balconies. Where? In one of these little streets tonight? The town would be dark and silent by one in the morning, if he could keep Dickie up that long. In the water? It was slightly cloudy, though not cold. Tom racked his brain [...] (HIGHSMITH, 1999, p. 101). mesmo o desejasse fazer, impedido mesmo pelo seu voyerismo -, mas somente compreender e esperar o que a narrativa apresentará como fato concreto. Ripley continua os seus planos:

San Remo. Flores. Uma caminhada ao longo da praia outra vez, lojas e turistas franceses, ingleses e italianos. Um outro hotel com flores nas varandas. Onde? Em uma dessas ruas pequenas hoje à noite? A cidade estaria escura e silenciosa uma da manhã, se ele pudesse manter Dickie acordado tanto tempo. $\mathrm{Na}$ água? Estava ligeiramente nublado, embora não frio. Tom queimava as pestanas [...](HIGHSMITH, 1999, p. 101). ${ }^{5}$

Aqui se observa como Ripley continua o seu esforço mental para encontrar uma solução. A focalização, tendo Ripley como referência, torna acessível ao(à) leitor(a), de forma fragmentada, como o personagem raciocina, como e o que ele vê, como se sente. Em ambos os trechos, a formatação do discurso, ao imitar o processo de pensamento, extrai da linguagem convencional um certo caráter icônico, que se apresenta tanto como incerteza quanto potência, possibilidade de significação. Além disso, as descrições e metáforas podem incrementar tal teor qualitativo, como se vê no trecho seguinte, que expõe o momento em que Ripley definitivamente se dá conta de que Dickie não o quer mais por perto:

Ele olhou fixamente nos olhos azuis de Dickie que ainda estavam franzidos, o branco das sobrancelhas decoradas pelo sol e os olhos brilhantes e vazios, nada mais que pedaços pequenos de geleia azul com um ponto preto dentro, sem significado, sem nenhuma relação com ele. Devia-se ver amor através dos olhos, o único lugar onde você poderia olhar outro ser humano e ver o que realmente estava lá dentro, e nos olhos de Dickie 
Tom não viu nada mais do que ele veria se olhasse a face dura e sem sangue de um espelho (HIGHSMITH, 1999, p. 91). ${ }^{6}$

A metáfora feita na descrição do olhar de Dickie como vazio, bem como a comparação entre os olhos dele e a face dura e sem sangue de um espelho, reforçam, ao menos potencialmente, a sensação de perigo que ronda, de ameaça, de risco de perda da vida. Não é amor que Ripley encontra nos olhos de Dickie, mas o seu próprio reflexo, rígido, uma auto-imagem sem vida. As metáforas e descrições frequentemente funcionam, em conjunto com os elementos icônicos citados e com o próprio conteúdo narrativo, como possibilidade de significação. Isso quer dizer que o contexto em que esses elementos aparecem faz com que eles ganhem tal qualidade e atuem no sentido aqui atribuído.

Para além dos aspectos formais, como acabamos de sugerir, o próprio conteúdo narrativo pode contribuir para a construção dos sentimentos e sensações do romance. A narrativa começa com Ripley fugindo de Herbert Greenleaf, a quem não conhecia e que desconfiava ser um agente da polícia que descobrira seus pequenos golpes. Antes, há a fuga de Tia Dottie, que tratava Ripley com um misto de sadismo e indiferença (HIGHSMITH, 1999, p. 37), os esconderijos e frequentes trocas de casa (p. 11; p. 26), as fraudes que tornam necessárias constantes dissimulações e a própria capacidade que o personagem tem de forjar e fingir. A recorrência de um tema - neste caso, a fuga e a clandestinidade atua potencialmente sobre a atmosfera da narrativa.

Após esses breves exemplos de elementos icônicos, tratemos agora dos índices ou elementos indexicais, aqueles que travam contato com o mundo e o contexto.

\subsection{Análise de signos indexicais}

Os índices são as referências do romance ao seu contexto,

6 He stared at Dickie's blue eyes that were still frowning., the sun-bleached eyebrows white and the eyes themselves shining and empty, nothing but little pieces of blue jelly with a black dot in them, meaningless, without relation to him. You were supposed to see love through the eyes, the one place you could look at another human being and see what really went on inside, and in Dickie's eyes Tom saw nothing more than he would have seen if he had looked at the hard bloodless face of a mirror (HIGHSMITH, 1999, p. 91). 
cia, a força das imagens é demonstrada contundentemente, como mostram os trechos abaixo:

[...] Tom permaneceu de pé, com as mãos na cintura, sua cabeça para cima. Em um grande espelho na parede ele pôde se ver: novamente o jovem ereto e respeitável [...] (p. 20).

\section{$[\ldots]$}

Mr. Greenleaf entrou na sala. Sua figura parecia pulsar e crescer mais e mais. Tom piscou os olhos, sentindo um repentino terror em relação a ele, um impulso para atacar antes de ser atacado [...].

É como um filme, pensou Tom. Em um minuto, a voz de Mr. Greenleaf ou de alguma outra pessoa diria, ‘OK, corta'!, e ele relaxaria de novo [...] (p. 21)7.

Percebe-se que o romance de Highsmith carrega em si referências imagéticas e meta-narrativas ao cinema e à fotografia. $\mathrm{O}$ primeiro dos trechos acima remete à imagem especular e ao fato de que o personagem se orienta pelas imagens que vê, além de se preocupar com a imagem que os outros podem fazer dele.

No segundo trecho, Ripley associa a forma como Mr. Greenleaf se aproxima dele a uma espécie de ameaça. A referência à imagem de Mr. Greenleaf se aproximando, como um movimento de câmera ameaçador e aterrorizante, é usada para revelar algo da subjetividade de Ripley, que age como um animal acuado, medroso, assustado com os seus próprios fantasmas. Afinal, não haveria motivo plausível para Mr. Greenleaf fazer-lhe algum mal, mas a própria consciência de Ripley, que sabia estar simulando

[...] Tom remained standing, his hands at his sides, his head high. In a large mirror on the wall he could see himself: the upright, self-respecting young man again $[\ldots]$ (p. 20).

[...]

Mr. Greenleaf came into the room. His figure seemed to pulsate and grow larger and larger. Tom blinked his eyes, feeling a sudden terror of him, an impulse to attack before he was attacked [...].

[...]

It's like a movie, Tom thought. In a minute, Mr. Greenleaf or somebody else's voice would say, 'Okay, cut!' and he would relax again [...] (p. 21). situações que agradassem ao pai de Dickie, parece fazê-lo imaginar algo irreal a partir do que estava vendo.

No terceiro trecho citado acima, há uma referência direta ao cinema, quando Ripley aparentemente constata a insanidade de sua própria imaginação. Além disso, toda a sequência é marcada pela encenação de Ripley diante do casal. Ripley finge interesse pelos assuntos, luta para não decepcionar os pais de Dickie, tenta se mostrar disponível, quando, na verdade, toda a situação beira o insuportável, chegando quase a fugir ao seu controle. O cinema aqui pode ser visto como uma simulação ou farsa por meio de imagens. No trecho seguinte pode-se notar mais uma vez a ocorrência de referências imagética e intertextual, constantes ao longo dos romances:

[Tom] sentiu que poderia desmaiar se ficasse mais um minuto naquele foyer mal iluminado, mas Mr. Greenleaf ria mais uma vez, perguntando-lhe se ele havia lido um certo livro de Henry James. 
'Lamento dizer que não, senhor, não esse', disse Tom.

'Bem, deixe pra lá, disse Mr. Greenleaf, sorrindo.

Então apertaram as mãos, um longo e sufocante aperto de Mr. Greenleaf, e acabou. Mas a expressão dolorida e assustada permanecia no seu rosto enquanto descia no elevador, percebeu Tom [...] (p. 24). ${ }^{8}$

O livro de Henry James, como é revelado depois, quando Ripley tenta comprá-lo no navio, é Os embaixadores, escrito em 1903. Nesse romance, é contada a história de Lewis Steher, que é incumbido da missão de trazer da Europa o filho da viúva Mrs. Newsome, chamado Chad. Steher tem um interesse direto em ser bem sucedido na sua tarefa, pois crê que as chances de casarse com a viúva aumentarão se conseguir lhe dar essa felicidade. Entretanto, Steher percebe que Chad está envolvido amorosamente em Paris, e que não seria correto convencê-lo a voltar para a América. Outros "embaixadores" são enviados, mas Steher se decide por agir da forma que considera moralmente correta, que é a desistência da tarefa inicial.

Obviamente, o parentesco de $O$ talentoso Ripley com o romance de Henry James é direto, pelo próprio motivo da história, e declarado, ao se fazer a citação. Assim, logo nas passagens iniciais do romance de Highsmith, pode-se antever a enxurrada de imagens e referências que constituirão a narrativa. $\mathrm{O}$ texto faz supor a inevitabilidade das citações e referências imagéticas, que, se não o saturam, fazem parte de sua composição de modo praticamente indissociável.

Também o romance Pacto sinistro, da própria Highsmith, e,

[Tom] felt that he could faint if he stayed one minute longer in the dimly lighted foyer, but Mr. Greenleaf was chuckling again, asking him if he had read certain book by Henry James.

'I'm sorry to say I haven't, sir, not that one', Tom said.

'Well, no matter.' Mr. Greenleaf smiled.

Then they shook hands, a long suffocating squeeze from Mr. Greenleaf, and it was over. But the pained, frightened expression was still on his face as he rode down the elevator, Tom saw [...] (p. 24).

9 O título original do romance de Highsmith e do filme de Hitchcock é Strangers on a train (Estranhos num trem). por extensão, sua adaptação para o cinema por Hitchcock, aparecem como referências narrativas intertextuais. Nessa história, Guy Haines conhece, em uma viagem de trem ${ }^{9}$, o perturbado Charles Anthony Bruno. A partir da conversa que se desenvolve entre os dois, Bruno fica sabendo que a esposa de Guy está criando problemas para lhe conceder o divórcio do qual precisa para poder casar-se outra vez. Por outro lado, Bruno demonstra nutrir um forte ódio pelo pai. Propõe, então, que os dois "troquem" crimes, cada um matando a pessoa que representa um problema para o outro, de forma que nenhum tipo de suspeita recaia sobre eles. A fala de Bruno, extraída do romance, pode esclarecer uma das relações que há entre as histórias:

[...] Mas eu não estou a fim de trabalhar. Não preciso, percebe? Não sou escritor, nem pintor, nem músico. Por que uma pessoa deve ser obrigada a trabalhar, se não precisa? Não passa de uma maneira de ter uma úlcera. Meu pai tem úlcera. Pois é. Ele ainda tem esperanças de que um dia eu participe do seu negócio de ferragens. Mas eu lhe digo que negócios, qualquer espécie de negócios, não passam de falcatruas legalizadas, do mesmo jeito que casamento é a fornicação legalizada. Não estou certo? (HIGHSMITH, 2006, p. 16). 
O diálogo entre os romances $O$ talentoso Ripley e Pacto sinistro parece claro, não somente em virtude da visão amarga presente em ambos, mas pelo argumento narrativo em si. Herbert Greenleaf pede a Ripley para buscar o seu filho na Europa, julgando que ele deveria voltar para assumir suas responsabilidades (HIGHSMITH, 1999, p. 5). Na Itália, Dickie Greenleaf dizia estudar pintura, mas na opinião de seu pai, ele não tinha nenhum talento (p. 6), fato comprovado por Ripley, ao ver as pinturas de Dickie (p. 60). O fato é que tanto Dickie quanto Bruno recusam-se a realizar o desejo do pai.

A utilização deliberada de referências intertextuais e imagéticas não é particularidade de um período ou movimento literário, sendo, em geral, um traço do próprio romance. Do mesmo modo, a proliferação de imagens torna inexorável a sua assimilação pela literatura, seja como uma questão cognitiva e relacionada à experiência de vida do autor, seja como um empréstimo por meio do qual a literatura luta por sua sobrevivência (CRUZ, 2003, p. 215). Ainda assim, as diversas referências intertextuais e imagéticas do romance em questão apontam para questões como intermediação do mundo por meio das imagens, a farsa, a fraude e a imitação, conforme poderemos concluir em seguida, ao tratarmos do terceiro nível de análise, no qual sugerimos um significado ou interpretação para o romance, com base nas análises anteriores.

\subsection{Análise de signos simbólicos}

Se em Crime e castigo (1866), de Dostoievski - um dos autores preferidos de Patricia Highsmith -, o personagem central tem o desejo de melhorar o mundo matando uma agiota e, sem planejar, acaba matando também a irmã da agiota, que tinha visto o corpo, no romance de Highsmith há também o planejamento de um homicídio e a ocorrência de um outro não planejado. Uma diferença fundamental, porém, é que Ripley não pensa em melhorar o mundo, a não ser o seu próprio. Além disso, Ripley não é descoberto e passa a desfrutar de uma vida relativamente tranquila, como podemos ver nos romances posteriores da série. Dificilmente se pode encontrar um traço de julgamento em relação às atitudes do personagem. Suas reflexões, transmitidas pelo narrador, demonstram o seu sentimento em relação aos outros ou às situações, mas não veiculam nenhum juízo moral a respeito de suas próprias atitudes e emoções. Por outro lado, nas suas relações e no seu modo de agir e pensar, Ripley parece se tratar de uma pessoa comum, que não se diferencia especialmente das outras.

O romance de Patricia Highsmith, ao passo que esclarece os acontecimentos do ponto de vista do personagem Thomas Ripley, o faz de forma pouco linear e com uma série de lacunas e interrogações. Não se sabe se alguém fez algo, mas sim que Ripley suspeita que isso aconteceu. As idas e vindas do seu pensamento, 
as narrativas espaciais, as constantes descrições de lugares, ações, gestos e expressões, sob a perspectiva de Ripley, dão um tom subjetivo que, ao mesmo tempo, potencialmente provoca no(a) leitor(a) uma cumplicidade com os sentimentos e atitudes de Ripley. Este não está certo o tempo todo, não é um herói infalível nem digno de admiração, mas é, parodiando Nietzsche, "humano, demasiado humano".

Considerando-se que todo discurso tem uma vontade de verdade (BARTHES, 1996-7, p. 43), a tese de Highsmith parece estar ligada à existência de uma ilegalidade difusa e de uma farsa subjacentes à própria sociedade. Se para Bruno, de Pacto sinistro, qualquer negócio é uma falcatrua legalizada (HIGHSMITH, 2006, p. 16), para Ripley, uma vida prazerosa seria aquela em que ele tivesse dinheiro o suficiente para colecionar peças de arte, ler bons livros (HIGHSMITH, 1999, p. 250), conhecer a arte de diversos países e ajudar jovens artistas talentosos que precisassem de dinheiro (p. 284). O Ripley de Highsmith sai impune e ainda fica com a herança de Dickie.

Posteriormente, no romance Ripley subterrâneo, saberemos que o personagem passa a investir também na falsificação de pinturas. Será um sujeito comum, amante das artes, casado e vivendo em uma pequena cidade perto de Paris. A ideia da farsa mencionada acima pode ser sustentada se analisamos as temáticas sugeridas ou abordadas, como a falsificação de pinturas, por meio da qual o pintor Derwatt, mesmo depois de morto, acaba se tornando cada vez mais renomado. Aquele que nota a farsa, o personagem Murchison, é eliminado por Ripley. Além disso, Tufts, que tinha sido discípulo do verdadeiro Derwatt e passa a ser cúmplice da fraude, sofre em sua consciência por sentir que está traindo o seu mentor e acaba cometendo suicídio. Ripley, sempre se reinventando, chega a se disfarçar de Derwatt, para, por meio de uma conferência de imprensa, provar que o pintor falsificado continua vivo. É insistente o tema do apagamento das diferenças, após o que tudo volta à sua (aparência de) normalidade.

Voltando ao romance O talentoso Ripley, os dias de Ripley, desde que ele conheceu Dickie, tinham sido dias da mais plena felicidade, a ponto de ele chegar a pensar que, mesmo se fosse descoberto e condenado à cadeira elétrica, tais dias teriam valido a pena:

[...] supondo que o pegassem pelas impressões digitais, ou pelo testamento, e sentenciassem-no à cadeira elétrica - será que a morte na cadeira elétrica poderia se igualar no sofrimento, ou a própria morte aos vinte e cinco anos seria tão trágica, a ponto de ele não poder dizer que os meses desde novembro até agora não tinham valido a pena? Certamente que não (HIGHSMITH, 1999, p. 284). ${ }^{10}$

O Ripley de Highsmith é um herói amoral, fiel somente aos seus sentimentos e gostos. Sonha conhecer outros países, especial- 
mente depois que a estada na Europa lhe despertou um grande interesse pelas artes e, em especial, a pintura (p. 284). Colecionaria pinturas e incentivaria novos artistas, se tivesse dinheiro. De fato, acaba recebendo o dinheiro de Dickie, pois o testamento forjado é aceito por Herbert Greenleaf. Ainda que tema, por alguns instantes, que encontrará policiais em todos os portos pelos quais passar, ele está livre (p. 290). A sua preocupação em ser descoberto algum dia parece ser simplesmente um traço ou uma fantasia de qualquer falsário - quando falsificava cartas de cobrança de impostos, em Nova York, também temia ser preso. No entanto, a vida que pretende levar é de contemplação e prazer, usufruindo das artes e provavelmente daquilo que o mundo tiver de melhor para lhe oferecer.

Nessa história, é colocada em xeque a diferenciação essencial entre certo e errado, bem e mal, verdadeiro e falso, o que acontece em virtude da própria estrutura da narrativa. De certa forma, o(a) leitor(a) tem conhecimento do que se passa na mente do anti-herói amoral Thomas Ripley e fica sujeito à sua simpatia. Pode-se dizer que o(a) leitor(a) corre o risco de cair em uma armadilha, uma vez que não é necessário concordar com os atos de Ripley para perceber o quanto os seus pensamentos e emoções são comuns e tipicamente humanos.

Por um lado, o personagem Ripley é aquele sujeito que consegue se livrar, mesmo com alguns arranhões, das diversas situações em que precisa manter o status que atingiu e do qual não deseja abdicar. Suas motivações podem parecer levianas do ponto de vista de uma ética humanista, mas não daquilo que faz sentido para o personagem de Highsmith: os bens materiais, as obras de arte, a livre circulação entre as cidades, as atividades simples do dia a dia. Tanto no que concerne à cultura e à arte, como ao ser humano e suas motivações, o personagem e os romances parecem advogar que o sistema que constrói as diferenças é o mesmo que as apaga, quando isso é conveniente.

Por outro lado, a construção do romance em questão tem como algumas de suas principais características o diálogo com outras obras e outras linguagens, como livros, filmes, o próprio cinema e as imagens, mas também a pintura e a música. Como meta-narrativa, o romance já carrega em si um confronto de dis-

${ }^{10}[\ldots]$ supposing they got him on the fingerprints, and on the will, and they gave him the electric chair - could that death in the electric chair equal in pain, or could death itself, at twenty-five, be so tragic, that he could not say that the months from November until now had not been worth it? Certainly not (HIGHSMITH, 1999, p. 284). cursos e ideologias, uma pluralidade de vozes (CRUZ, 1997, p. 11).

Entre as características da condição pós-moderna está a ênfase na imagem, a qual tem sido multiplicada pela fotografia e pelo cinema (e ainda mais intensamente na atualidade, por meio das mídias digitais). A literatura tem incorporado, em sua própria estrutura, bem como nas escolhas temáticas, essa característica tão marcante e sem sinais de arrefecimento na cultura atual (CRUZ, 1997, p. 6-9). Se seguirmos esse raciocínio, poderemos supor que o personagem Tom Ripley pode ser considerado como criação de uma lógica em que a força da imagem sobre os sentidos já se 
faz presente. A reprodução de imagens, da forma como se dá em nossa cultura contemporânea, frequentemente designada como pós-moderna, denota e implica uma saturação de cópias do mundo atual. Diminui o contato direto do sujeito com os objetos, sejam eles materiais ou abstratos, e o conhecimento ocorre sob a intermediação das imagens, como em alguns exemplos citados anteriormente - por exemplo, quando Ripley começa a conhecer Dickie pelas fotografias.

\section{Comentários finais}

Esta breve análise do romance, na qual aplicamos a proposta metodológica esboçada, deve ser vista, em primeiro lugar, como um exemplo possível, entre muitos outros, e que pode ser desenvolvido e tomar outras direções. Para a análise da construção de sentimentos e das possibilidades de significação, na qual reconhecemos a categoria da primeiridade, diversos outros fatores poderiam ser tomados em consideração, como a estrutura das orações e dos períodos, a escolha lexical etc.. Similarmente, a identificação de elementos relacionados à categoria da secundidade (como outros intertextos, dêiticos e fatos), assim como a discussão sobre a interpretação provisória, poderiam seguir caminhos os mais variados. Entretanto, uma vez que nosso objetivo é delinear uma proposta metodológica no âmbito restrito de um artigo, os resultados encontrados parecem suficientes para prosseguirmos com a discussão.

Sendo um romance particular a tradução de uma ideia para o código literário do gênero 'romance', sua análise semiótica idealmente deve permitir tanto a identificação da ideia traduzida, quanto dos processos semióticos utilizados para veiculá-la. Adicionalmente, tal análise pode proporcionar uma maior compreensão do próprio gênero narrativo em questão, ao menos da maneira como ele era concebido no momento de sua produção.

De fato, pudemos identificar instâncias de signos icônicos e indexicais utilizados na composição do romance, bem como um interpretante plausível, obtido a partir das análises iniciais. Podemos afirmar que elementos marcantes do romance em questão, como as narrativas espaciais, as descrições e metáforas, bem como a recorrência de temas, situam-se no campo do icônico, da primeiridade. Com isso, podemos supor que esses elementos ou são características do romance, ou do romance da época (meados do século XX), e testar essa hipótese em outros romance. Por outro lado, é possível que encontremos, na análise de outras obras, signos icônicos diferentes destes observados aqui.

Em relação aos signos indexicais, hipóteses semelhantes podem ser levantadas. Por exemplo, a intertextualidade que destacamos no romance, apesar de ser uma característica presente em toda a literatura, provavelmente é utilizada, em determinadas 
obras, de forma deliberada, para, por exemplo, sustentar a ideia defendida pelo romance. Pode-se supor que a exacerbação do uso da intertextualidade faça parte da poética contemporânea. As referências imagéticas do romance em questão, ao passo que concorrem para sustentar ainda mais o tema da farsa, da cópia e da fraude, refletem os signos que estão presentes no contexto de surgimento do romance, no qual os objetos são mediados por suas representações. É possível se investigar como as mídias digitais e a cibercultura têm reconfigurado a literatura, da mesma maneira que a fotografia e o cinema têm feito desde o advento destes sistemas de signos.

No que concerne ao interpretante, a exemplo da análise aqui realizada, acaba se constituindo em um meta-signo ou tradução na forma de um outro texto, desta vez acadêmico. Assim, a análise apresentada no item 2 anterior é uma tradução do romance para um artigo acadêmico. Este mesmo texto, sendo signo, é uma tríade, formada pelo representamen (o próprio texto), o seu objeto (o romance $O$ talentoso Ripley) e o interpretante (aquilo que a referida análise apresentada gera na mente de quem a lê).

O signo aqui gerado oferece uma visão parcial, que pode continuar sendo infinitamente desenvolvida e colocada em contato com outras visões. O objetivo deste processo é fazer o interpretante voltar-se para objeto, o que é a função mesma do signo. A percepção aqui exposta de $O$ talentoso Ripley, como sendo a denúncia de uma farsa disseminada na sociedade, onde as cópias se multiplicam e as imagens substituem os objetos - assim como o dinheiro suspende a moral -, é, portanto, um interpretante que tentamos fazer voltar-se para o objeto, mas que, ao mesmo tempo, o fabrica. Em um mundo cada vez mais mediado, o objeto, se algum dia existiu, parece estar para sempre perdido.

De qualquer sorte, uma das vantagens da metodologia apresentada é a orientação do processo de análise do texto literário de forma que tanto suas características internas quanto as relações estabelecidas pelo texto com o contexto exterior sejam igualmente consideradas. Além disso, é requisito lógico da proposta que o(a) analista se insira na própria análise, por meio das relações que ele mesmo estabelece entre o texto investigado e outros textos, teorias e conhecimentos, sem que a análise se reduza a impressões subjetivas e opiniões pouco embasadas, nem tampouco caia na ilusão da objetividade pura. Antes, a abordagem que apresentamos permite um exercício interdisciplinar virtualmente ilimitado. Uma outra vantagem está na percepção de que todas as coisas funcionam como signos, não havendo hierarquia entre os seus diferentes tipos e formas de apresentação. Por exemplo, um romance pode, em algum caso, ser a tradução de uma teoria ou de um tratado filosófico, e a identificação deste fato depende das ferramentas das quais dispõe o(a) leitor(a) ou analista. 


\begin{abstract}
This paper proposes a methodological approach of the novel based on Charles Sanders Peirce's semiotics, by using the universal categories of the firstness, secondness and thirdness for analysis of literary texts. A brief analysis of the novel The Talented Mr. Ripley, by Patricia Highsmith, is made, in order to demonstrate the applicability and relevance of the proposed methodology. It was concluded that, given the contemporaneous complexity in terms of the multiplication of signs, the approach can be advantageous for requiring the analysis of the aspects of the novel, without neglecting the participation of the analyst's own subjectivity.
\end{abstract}

Keywords: Novel; semiotics; methodology

\title{
REFERÊNCIAS
}

BARTHES, Roland. Aula: Aula inaugural da cadeira de semiologia literária do Colégio de França. Tradução e pósfácio de Leila Perrone-Moysés. São Paulo: Cultrix, 1996-7.

CINÉMA Cinemas 66. Don Kent; Joan Dupont; Patricia Highsmith: 6 parts, starting with "Good Morning, Vietnam" with Robin Williams; No. 6: Patricia Highsmith (A2). 11 set. 1988. 66' (Highsmith part from $30^{\prime}$ to $40^{\prime}$ ). VHS, son., color. Fr.

CRUZ, Décio Torres. Post-modern meta-narratives: literature in the age of image. Scott's Blade Runner and Puig's novels. 1997. $302 f$. Tese (Doutorado em Literatura Comparada). State University of New York, Buffalo.

2003.

O pop: literatura, mídia e outras artes. Salvador: Quarteto,

HIGHSMITH, Patricia. The talented Mr. Ripley, Ripley under ground, Ripley's game. New York: Everyman's, 1999.

. Pacto sinistro. Tradução Tite de Lemos. Rio de Janeiro:

Ediouro, 2006.

LIMA DE SANTANA, Sergio Ricardo. As várias faces de Ripley: entre a literatura e as adaptações cinematográficas. 2009. 254 f. Tese (Doutorado em Letras e Linguística) - Universidade Federal da Bahia, Salvador.

PEIRCE, Charles Sanders. Semiótica. São Paulo: Perspectiva, 1999. SANTAELLA, Lucia. Por uma classificação da linguagem escrita. In: Produção de linguagem e ideologia. São Paulo: Cortez, 1980. p. 143-160.

. A assinatura das coisas: Peirce e a literatura. Rio de Janeiro: Imago, 1992. 
. A teoria geral dos signos: como as linguagens significam as coisas. São Paulo: Pioneira Thomson Learning, 2004. . Matrizes da linguagem e pensamento: sonora visual verbal: aplicações na hipermídia. 3. ed. São Paulo: Iluminuras, Fapesb, 2005.

WALTHER-BENSE, Elisabeth. A teoria geral dos signos. São Paulo: Perspectiva, 2000. 